\title{
LICHT AM ENDE DES TUNNELS
}

\section{Liebe Kolleginnen und Kollegen!}

Die Corona-Pandemie hält uns immer noch in Atem, obschon sich gegen den Sommer zu langsam eine Entspannung abzeichnet. Dazu trägt die Impf-Kampagne ihren gewichtigen Teil bei. Gerade in Praxen mit komplementärmedizinischem Angebot sind wir gehäuft mit Fragen zur Impfung konfrontiert. Die Omnipräsenz des Themas in den Medien mit ausgesprochen polarisierten Meinungen, mit einem gewissen Drall zur Dramatisierung führt bei vielen Patienten zurVerunsicherung. Dazu kommt, dass die mRNA-Impfungen eine neue Technologie sind. In der Schweiz werden zum Zeitpunkt ausschließlich mRNA-Impfstoffe verwendet. Das Nebenwirkungsprofil dieser Impfungen scheint nach bisherigem Wissen relativ günstig. Doch wie verhält es sich im Einzelfall? In dieser Situation hilft uns, wie so oft, der RAC weiter. Haben wir in der Praxis die Impfstoffe zurVerfügung, können wir sie elegant auf die energetische Verträglichkeit austesten. Die Erfahrung von mehreren Ärztekollegen, die diese Testung machen, ist grundsätzlich günstig. Es zeigte sich jedoch in den meisten Fällen eine leichte Schwächung des Yintang, entsprechend Energiemeridian EN 6 nach Bahr. Mit der australischen Living-Essenz Swan River Myrtle (Zuordnung nach Bahr) lässt sich diese Schwäche elegant beheben. Die Dosierung beträgt drei Tropfen, über den Tag verteilt, während sieben Tagen, beginnend am Tag der Impfung.

Die Ausbildungskurse für den Fähigkeitsausweis konnten während der zweiten und dritten Welle der Pandemie glücklicherweise ohne Probleme durchgeführt werden, wenn auch fast ausschließlich online. Hospitationskurse, wie wir sie in der Ohrakupunktur durchführen, bedingen aber Präsenz. Mit Räumlichkeiten mit Frischluftzufuhr und FFP2-Masken wurde aber auch das möglich gemacht, sodass alle Module regelgerecht am 12. Juni mit der Prüfung abgeschlossen werden können. Erfrischend war es, dass wir zudem am 8. Mai den Kurs „Linie der Tumoren“ durchführen konnten. Es war der erste Fortbildungskurs im Präsenz-Modus seit längerer Zeit.

Ihr

Christoph Scholtes

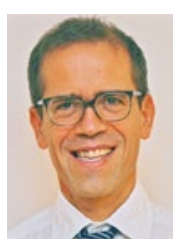

Dr. med. Christoph Scholtes

Co-Präsident der Schweizerischen Ärztegesellschaft für Akupunktur - Chinesische Medizin - Aurikulomedizin, SACAM

Wattenwylweg 21, 3006 Bern

Tel. +41(0)844200200

info@sacam.ch, www.sacam.ch 